\title{
Non-invasive surveillance for Plasmodium in reservoir macaque species
}

\author{
Josephine E. Siregar ${ }^{1}$, Christina L. Faust ${ }^{2}$, Lydia S. Murdiyarso ${ }^{1}$, Lis Rosmanah ${ }^{3}$, Uus Saepuloh ${ }^{3}$, \\ Andrew P. Dobson ${ }^{2}$ and Diah Iskandriati ${ }^{3}$
}

\begin{abstract}
Background: Primates are important reservoirs for human diseases, but their infection status and disease dynamics are difficult to track in the wild. Within the last decade, a macaque malaria, Plasmodium knowlesi, has caused disease in hundreds of humans in Southeast Asia. In order to track cases and understand zoonotic risk, it is imperative to be able to quantify infection status in reservoir macaque species. In this study, protocols for the collection of non-invasive samples and isolation of malaria parasites from naturally infected macaques are optimized.
\end{abstract}

Methods: Paired faecal and blood samples from 60 Macaca fascicularis and four Macaca nemestrina were collected. All animals came from Sumatra or Java and were housed in semi-captive breeding colonies around West Java. DNA was extracted from samples using a modified protocol. Nested polymerase chain reactions (PCR) were run to detect Plasmodium using primers targeting mitochondrial DNA. Sensitivity of screening faecal samples for Plasmodium was compared to other studies using Kruskal Wallis tests and logistic regression models.

Results: The best primer set was $96.7 \%$ (95 \% confidence intervals (CI): 83.3-99.4\%) sensitive for detecting Plasmodium in faecal samples of naturally infected macaques $(n=30)$. This is the first study to produce definitive estimates of Plasmodium sensitivity and specificity in faecal samples from naturally infected hosts. The sensitivity was significantly higher than some other studies involving wild primates.

Conclusions: Faecal samples can be used for detection of malaria infection in field surveys of macaques, even when there are no parasites visible in thin blood smears. Repeating samples from individuals will improve inferences of the epidemiology of malaria in wild primates.

Keywords: Malaria, Macaca fascicularis, Macaca nemestrina, Non-invasive sampling, Zoonotic surveillance

\section{Background}

Non-human primates (NHPs) are important hosts of zoonotic diseases: they can share pathogens with humans and act as reservoirs for several emerging infectious diseases of pandemic proportions [1-4]. NHPs are also susceptible to human pathogens that can have mild to catastrophic impacts on populations [5-9]. In order to predict zoonotic risk and understand conservation implications of pathogen exchange between humans and NHPs, it is essential to understand infectious disease dynamics within wild primate populations.

\footnotetext{
*Correspondence: cfaust@princeton.edu

2 Department of Ecology and Evolutionary Biology, Princeton University,

Princeton, NJ 08544, USA

Full list of author information is available at the end of the article
}

Primates are infected with at least thirty Plasmodium parasites globally $[10,11]$. Spillover of NHP malaria has been suspected in cases in the Amazon [12-14] and a tourist returning from Central Africa [15]. On a much larger scale, a monkey malaria, Plasmodium knowlesi, has emerged in human populations across Southeast Asia (Fig. 1, Additional file 1). The parasite species has been recorded, and is presumably endemic, in wild populations of two macaque species (Macaca fascicularis and Macaca nemestrina) and two leaf monkeys (Presbytis femoralis and Trachypithecus obscurus) [16-19]. These primates can be co-infected with up to five species of Plasmodium parasite [20], but most morphological surveys report moderate (10-30\%) malaria prevalence in long-tailed macaques (Fig. 1, see Additional file 1). While spillover cases have 


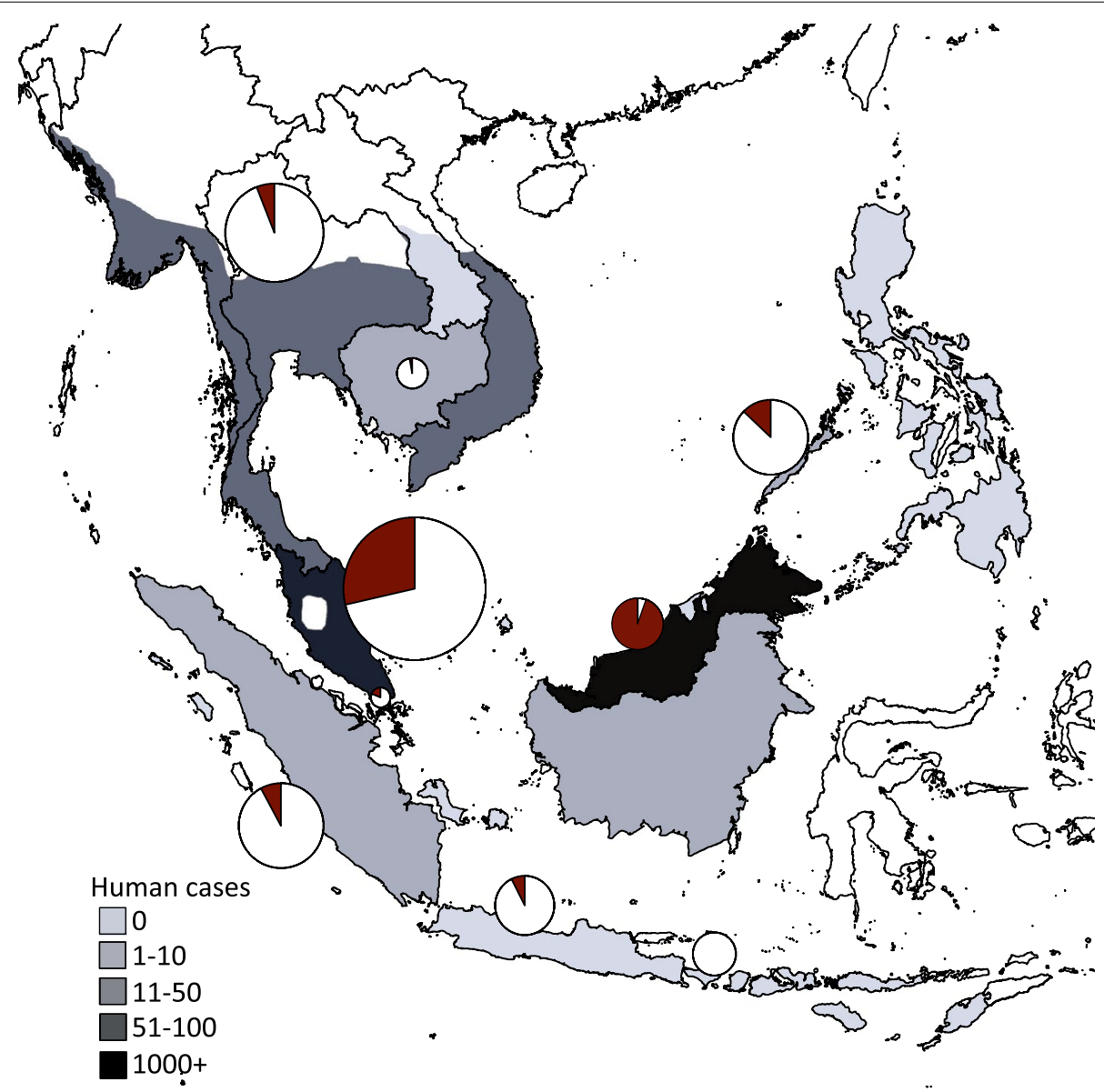

Fig. 1 Macaque malaria in long-tailed macaques and humans in Southeast Asia. The number of human P. knowlesi cases that have originated from the location is represented in shades of grey. The maximum range of Macaca fascicularis [50] is greater than the extent of known P. knowlesi spillover cases. Pie charts depict cumulative results of parasitological and molecular surveys of malaria (all five Plasmodium species) in long-tailed macaques, with the size of the circle corresponding to sample size from the given location. Referenced raw data are given in Additional file 1

increased in incidence in some regions over the last decade [21, 22], there is no evidence for human-to-vectorto-human transmission, therefore quantifying malaria dynamics within reservoir populations is essential.

While large foci of zoonotic malaria is currently restricted to Southeast Asia, this spillover presents a unique opportunity to document processes underlying the evolution of malaria. Plasmodium falciparum and Plasmodium vivax, the most important human malaria parasites, are the result of host switches from NHPs [15, 23-26]. Malaria is the most important human infectious disease globally, causing hundreds of thousands of deaths and disease in millions annually [27]. Understanding the dynamics in wild primates will only improve our understanding of the underlying drivers of infection in humans.

Non-invasive sampling methods are the primary tool for primate infectious disease ecology, because many times logistical challenges and ethical considerations prohibit collection of blood and tissues. Non-invasive sampling methods have been used to successfully study parasites across taxa, with the majority of studies focusing on parasites that are transmitted through a faecaloral route [28-30]. However, researchers have recently used faecal samples to study malaria parasites in apes in Central Africa and have been able to isolate Plasmodium DNA from human stool samples $[15,23,25$, 26, 31] (see Additional file 2). While isolation of Plasmodium DNA has been successful, there are no robust estimates of how presence of Plasmodium DNA in faeces translates to disease status and prevalence among populations.

The objectives of this study were to determine if noninvasive sampling is a reliable method for tracking Plasmodium reservoir dynamics in monkeys of Southeast 
Asia. Paired samples from semi-captive Indonesian long-tailed macaques (M. fascicularis) and pig-tailed macaques ( $M$. nemestrina) that were naturally infected were used for validation. Protocols were developed and optimized to detect any of five Plasmodium species that infect these macaques.

\section{Methods}

\section{Sample collection}

Individual macaques of $M$. facscicularis originating from Lampung $(\mathrm{n}=30)$ and Palembang $(\mathrm{n}=30)$, Sumatra, and $M$. nemestrina originating from Java $(\mathrm{n}=4)$ were used as sources for paired blood and faecal samples. Animals were sedated for blood collection as a part of routine health screening at the breeding facilities in West Java. Blood samples were collected in EDTA tubes and, at the same time, thin blood smears were made from all $M$. fascicularis. Faecal swabs were taken at the time of sedation for the $M$. fascicularis (200-300 mg) and whole faeces were obtained from cages of Macaca nemestrina. Initial pilot work with $M$. nemestrina samples (see Additional file 3) demonstrated that samples stored in RNAlater ${ }^{\circledR}$ (Qiagen) had consistently higher DNA yield, so all faecal samples were stored in sterile vials in a 1:1 ratio with RNAlater. Samples were transferred to $-20{ }^{\circ} \mathrm{C}$ as soon as possible (within $24 \mathrm{~h}$ ) until extraction. Paired blood was frozen at $-20{ }^{\circ} \mathrm{C}$ immediately after collection. All procedures involving animals were approved by Institutional Animal Care and Use Committee, Primate Research Center, Bogor Agricultural University number IPB PRC-13-A012.

\section{Molecular analysis}

DNA was extracted from faecal samples using a modified protocol from the QIAamp Mini Stool Kit (Qiagen ${ }^{\circledR}$ ). Samples were lysed in ASL buffer overnight with intermident vortexing to increase DNA yield; the rest of the protocol was followed as per manufacturer instructions. Filter pipette tips were used in all stages of processing to prevent cross-contamination. Screening for malaria parasites was done using three primer sets targeting cytochrome b (cytb) and one set targeting a fragment of the mitochondrial small subunit rRNA (ssrRNA) in Plasmodium (Table 1). Each cytb primer set was tested in two replicates for each faecal and blood sample originating from one individual. The ssrRNA primers were only tested on a subset $(n=32)$ due to limited reagents.

Three sets of nested PCR were used to amplify the cytochrome $b$ gene; two sets were designed specifically for this study. The first nested primer set was PfF3700/ PfR4615 and targeted a $915 \mathrm{bp}$ fragment. The second PCR reaction utilized the first product with primer set PfF 3700/PfR4102 targetting a 402 bp fragment. The first nested PCR reaction was run with $2 \mu \mathrm{L}$ of template, while the second was run with $1 \mu \mathrm{L}$ of product from the first round reaction. Both PCRs were run using KAPA Taq DNA Polymerase (KAPA Biosystems, USA) under the following conditions: $5 \mathrm{~min}$ denaturation at $94{ }^{\circ} \mathrm{C}$, 30 cycles of $15 \mathrm{~s}$ denaturation at $94{ }^{\circ} \mathrm{C}, 15 \mathrm{~s}$ annealing at $50{ }^{\circ} \mathrm{C}, 45 \mathrm{~s}$ extension at $72{ }^{\circ} \mathrm{C}$, and a final extension of $5 \mathrm{~min}$ at $72{ }^{\circ} \mathrm{C}$.

The second nested reaction designed for this study first used the primer set PfF3368/PfR4102 targeting a 734 bp

Table 1 Primers and sensitivity for amplifying Plasmodium from faecal samples

\begin{tabular}{|c|c|c|c|c|c|c|}
\hline ID & Primer sets & Nest? ${ }^{a}$ & Sequence & $\begin{array}{l}\text { Product length } \\
\text { (bp) }\end{array}$ & Gene & $\begin{array}{l}\text { Reference } \\
\text { for primers }\end{array}$ \\
\hline ssrRNA & $\begin{array}{l}\text { PfF4595 } \\
\text { PfR5019 }\end{array}$ & reamp & $\begin{array}{l}\text { GATTACAGCTCCCAAGCAAAC } \\
\text { GTTTAGCCAGGAAGTCAGCGTC }\end{array}$ & 424 & ssrRNA & This paper \\
\hline cytb1 & $\begin{array}{l}\text { PfF3700 } \\
\text { PfR4615 }\end{array}$ & nest1a & $\begin{array}{l}\text { TGGATGGTGTTTTAGATACATGC } \\
\text { GTTTGCTTGGGAGCTGTAATC }\end{array}$ & 915 & cytb & This paper \\
\hline cytb1 & $\begin{array}{l}\text { PfF3700 } \\
\text { PfR4102 }\end{array}$ & nest2a & $\begin{array}{l}\text { TGGATGGTGTTTTAGATACATGC } \\
\text { GCTGTATCATACCCTAAAG }\end{array}$ & 402 & cytb & This paper \\
\hline cytb2 & $\begin{array}{l}\text { PfF3368 } \\
\text { PfR4102 }\end{array}$ & nest1b & $\begin{array}{l}\text { TGCCTAGACGTATTCCTGAT } \\
\text { GCTGTATCATACCCTAAAG }\end{array}$ & 734 & cytb & This paper \\
\hline cytb2 & $\begin{array}{l}\text { PfF3368 } \\
\text { PfR3717 }\end{array}$ & nest $2 b$ & $\begin{array}{l}\text { TGCCTAGACGTATTCCTGAT } \\
\text { TATCTAAAACACCATCCACTCCA }\end{array}$ & 349 & cytb & This paper \\
\hline cytb3 & $\begin{array}{l}\text { qPlasm1f } \\
\text { qPlasm1r }\end{array}$ & nest1c & $\begin{array}{l}\text { CTGACTTCCTGGCTAAACTTCC } \\
\text { CATGTGATCTAATTACAGAAYAGGA }\end{array}$ & 170 & cytb & [32] \\
\hline cytb3 & $\begin{array}{l}\text { qPlasm2f } \\
\text { qPlasm2r }\end{array}$ & nest2c & $\begin{array}{l}\text { AGAAAACCGTCTATATTCATGTTTG } \\
\text { ATAGACCGAACCTTGGACTC }\end{array}$ & 90 & cytb & [32] \\
\hline
\end{tabular}

Primers are all listed in the $5^{\prime}$ to $3^{\prime}$ end

a Nested reactions are indicated: the first primer set is denoted with ' 1 ' and the second set is denoted with ' 2 ', and nested primer sets can be differentiated by the letter following the number. Sensitivity is only given for the complete nested reaction. The primer set targeting the ssrRNA segment was used twice in a re-amplification reaction to increase yield 
fragment, followed by a nested reaction with the primer set PfF3368/PfR3717 targetting a 349 bp fragment. The reaction conditions were the same as above.

PCR amplifying a fragment of ssrRNA of mitochondrial Plasmodium utilized reamplification with primer set PfR4595/PfR5019. The amplified target was a $424 \mathrm{bp}$ fragment (Table 1). Both PCRs were run using KAPA Taq DNA Polymerase (KAPA Biosystems, USA) under the following conditions: $5 \mathrm{~min}$ denaturation at $94{ }^{\circ} \mathrm{C}$, 30 cycles of $15 \mathrm{~s}$ denaturation at $94{ }^{\circ} \mathrm{C}, 15 \mathrm{~s}$ annealing at $56^{\circ} \mathrm{C}, 45 \mathrm{~s}$ extension at $72{ }^{\circ} \mathrm{C}$, and a final extension of 5 min at $72{ }^{\circ} \mathrm{C}$.

An additional nested PCR was conducted with primers developed for detection of Plasmodium in chimpanzees [32]. The first round of PCR was run with primers qPlasm1f/qPlasm1r targeting a 170 bp segment of cytb under the following conditions: $3 \mathrm{~min}$ denaturation at $96{ }^{\circ} \mathrm{C}, 30$ cycles of $30 \mathrm{~s}$ denaturation at $96^{\circ} \mathrm{C}, 30 \mathrm{~s}$ annealing at $52^{\circ} \mathrm{C}, 1 \mathrm{~min}$ extension at $72{ }^{\circ} \mathrm{C}$, and a final extension of $5 \mathrm{~min}$ at $72{ }^{\circ} \mathrm{C}$. The second round of PCR was conducted with primer qPlasm2f/qPlasm2r resulting in a 90 bp product under the following conditions: $5 \mathrm{~min}$ denaturation at $95{ }^{\circ} \mathrm{C}, 30$ cycles of $15 \mathrm{~s}$ denaturation at $96{ }^{\circ} \mathrm{C}, 15 \mathrm{~s}$ annealing at $50^{\circ} \mathrm{C}, 30 \mathrm{~s}$ extension at $60^{\circ} \mathrm{C}$, and a final extension of $5 \mathrm{~min}$ at $60^{\circ} \mathrm{C}$.

All PCR reactions were run with a $25 \mu l$ PCR mixture: 1-2 $\mu \mathrm{l}$ of template, $2.5 \mu \mathrm{l}$ of 10X Kapa Taq PCR buffer (standard Tris-ammonium sulfate-based buffers containing $15 \mathrm{mM} \mathrm{MgCl}{ }_{2}$; KapaBiosystems, USA), $10 \mathrm{pmol}$ of each primer, $100 \mu \mathrm{M}$ of dNTPs (Promega), $0.5 \mathrm{U}$ of Taq DNA Polymerase (KapaBiosystems, USA). All PCR reactions were run with negative and positive (P. inui isolate) controls.

Positive PCR products were purified (Qiagen PCR Purification Kit) and directly sequenced using Forward and Reverse primer for PCR cytochrome $b$ and fragment ssrRNA of mitochondrial Plasmodium in an ABI 3130 XL Genetic Analyzer. The sequences obtained were BLAST to the reference sequences and aligned using the BioEdit program (Ibis Biosciences, CA, USA) to determine identity of Plasmodium species.

\section{Microscopy}

Thin blood smears were prepared by spreading two drops of fresh blood on a slide. Slides were dried and fixed with methanol. Dried slides were stained with $10 \%$ Giemsa solution. Each slide was examined under light microscope in all fields of slide by at least two trained malariologists. Parasite morphology was used to identify species following Coatney et al. [11].

\section{Statistical analysis}

Several statistics were calculated for each primer set used to detect Plasmodium species in faecal samples. (1) Sensitivity was calculated as the proportion of infected macaques (as defined by PCR positive in blood) that were PCR positive by faecal screening. Because sample sizes were low, $95 \%$ confidence intervals were calculated using a Wilson score interval [33]. (2) Specificity was measured as the proportion of uninfected macaques (again, defined as PCR negative in the blood) identified as PCR negative in the faecal samples. The last statistic in the diagnositics was the (3) false negative rate (FNR), which was the number of false negatives (PCR negative in faeces but PCR positive in blood) divided by the sum of the false negatives and true positives. A lower false negative rate is preferred for estimating population prevalence.

Sensitivity of the screening in this study was compared to other studies using primate faecal samples (including humans) to detect malarial DNA (Fig. 2, raw data, Additional file 2). A logisitic regression was fit to data from all the studies, using amplicon length, average adult female mass of host species, storage media, and PCR protocols as predictor variables in a logisitc regression using function $\mathrm{glm}$ in R vs 3.0.2 [34]. Predictor variables were chosen because they had data for all the studies in the analysis and were expected to influence DNA quality and diagnostic ability. If any of the variables significantly influence the sensitivity of protocols running a logisitic regression should be able to determine its magnitude and directionality.

\section{Results}

Sensitivity of primers for screening macaque faeces

Overall, 34 of 64 macaques $(53.1 \%)$ were infected with malaria (Table 2). Active infections were determined with PCR of blood samples and was considered a reflection of the true prevalence of infection. Thin blood films detected 17 (56.7 \%) of the 30 positive Macaca fascicularis individuals.

Primer sets varied in their sensitivity and false negative rate for detection of Plasmodium in faecal samples, but not their specificity (Table 3). Faecal screening never yielded a false positive. The maximum sensitivity was achieved with ssrRNA primers and was $96.7 \%$ (83.3-99.4\%).

Because of the limited volume of samples, DNA extraction could not be repeated. It is possible that extraction steps affected the estimates of sensitivity in these samples. Additional studies are warranted to examine if repeating extractions, in addition to $\mathrm{PCR}$ reactions, can increase the sensitivity of the assay. 


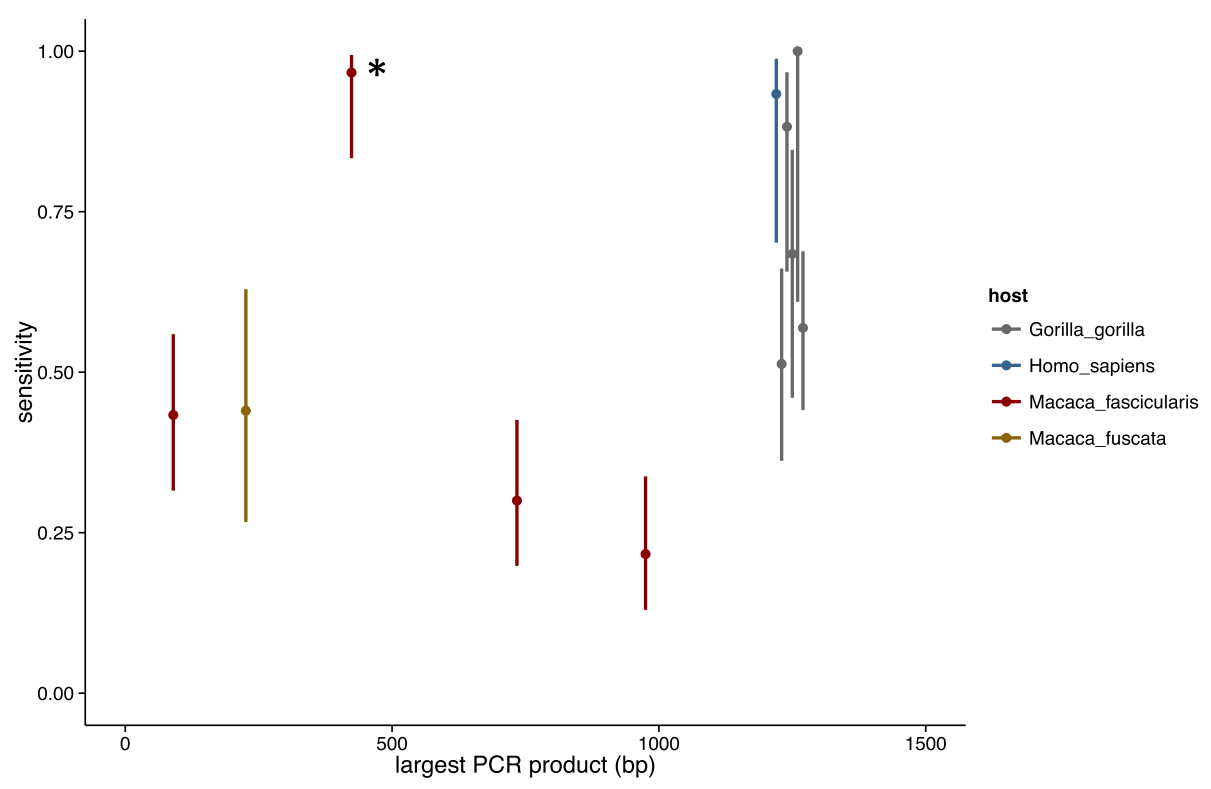

Fig. 2 Sensitivity of faecal screening for detection of Plasmodium infections in primates. Estimates for the sensitivity of screening faecal samples for Plasmodium from this study and previously published studies are shown (Additional file 2, [26, 31, 40]). The largest PCR product from all samples of gorillas and humans was $1230 \mathrm{bp}$, but are shown staggered in the figure for visual clarity. Confidence intervals are calculated using the Wilson interval for samples under 40 and the Agresti-Coull method for datasets that have 40 or greater sampling units. All calculations were done using the binom package [51] in R v. 3.0.2 [34]. The asterisk indicates the sensitivity of the best primers from this study

Table 2 Malaria infections of Macaca individuals determined by invasive samples

\begin{tabular}{llrll}
\hline Species & Origin & N & PCR + blood & $\begin{array}{l}\text { Sensitivity } \\
\text { of microscopy }\end{array}$ \\
\hline M. nemestrina & West Java & 4 & $4(100 \%)$ & NA \\
M. fascicularis & Lampung & 30 & $6(20 \%)$ & $3(50 \%)$ \\
M. fascicularis & Palembang & 30 & $24(80 \%)$ & $14(58.3 \%)$ \\
\hline
\end{tabular}

\section{Species of Plasmodium}

Plasmodium cytochrome $b$ genes from all positive blood samples of $M$. fascicularis were sequenced. Sequencing ssrRNA was insufficient to determine species identity. The majority of malaria infections were caused by Plasmodium inui (23 samples from Palembang, six samples from Lampung). Two isolates (one from each Palembang and Lampung) clustered more closely with GenBank samples identified as Plasmodium fieldi and Plasmodium cynomolgi but a specific species could not be assigned.

\section{Sensitivity of PCR for Plasmodium across primate species}

A Kruskal-Wallis test on the entire dataset failed to demonstrate a significant difference in sensitivity across all samples $(\mathrm{df}=10, \mathrm{p}=0.4405)$. Although this shows that differences were not significantly different globally, multivariate regressions were used to determine if predictor variables could explain differences in sensitivity. Both logistic regression and quasibinomial regressions were insufficient in elucidating factors that affected variation in the sensitivity. None of the predictor variables significantly impacted sensitivity, suggesting the models are not

Table 3 Sensitivity, specificity, and false negative rate of each primer set in faecal samples

\begin{tabular}{|c|c|c|c|c|c|c|c|c|}
\hline & \multirow{2}{*}{$\begin{array}{l}\text { Number of } \\
\text { faecal samples }\end{array}$} & \multirow{2}{*}{$\begin{array}{l}\mathrm{PCR}+\text { in paired } \\
\text { blood sample }\end{array}$} & \multicolumn{3}{|l|}{1 PCR run } & \multicolumn{3}{|l|}{2 PCR runs } \\
\hline & & & Sensitivity ${ }^{a}$ & Specificity & FNR $^{b}$ & Sensitivity & Specificity & FNR \\
\hline ssrRNA & 32 & 30 & $96.7 \%$ (83.3-99.4\%) & $100 \%$ & 0.03 & NA & NA & NA \\
\hline cytb-a & 64 & 34 & $29.4 \%(16.8-46.2 \%)$ & $100 \%$ & 0.71 & $29.4 \%(19.9-41.2 \%)$ & $100 \%$ & 0.71 \\
\hline cytb-b & 64 & 34 & $29.4 \%(16.8-46.2 \%)$ & $100 \%$ & 0.71 & $23.5 \%(14.9-35.0 \%)$ & $100 \%$ & 0.76 \\
\hline cytb-c & 64 & 34 & $41.2 \%(26.4-57.8 \%)$ & $100 \%$ & 0.59 & $41.2 \%(30.2-53.0 \%)$ & $100 \%$ & 0.59 \\
\hline
\end{tabular}

${ }^{a}$ The sensitivity is the percentage of infected macaques that are positive by PCR from faecal samples. $95 \%$ confidence intervals (CI) are given in parenthesis

${ }^{b}$ FNR is the false negative rate, or the number of false negatives divided by the sum of false negatives and true positives 
including all relevant variables. Increasing sample sizes and consistent molecular methods across a diversity of species will help elucidate important predictors of sensitivity of faecal samples for Plasmodium detection.

\section{Discussion}

Active macaque malaria infections can be detected in faecal samples using protocols developed in this study with 96.7 \% (95 \% CI: 83.3-99.4 \%) sensitivity. This assay is significantly better than thin blood smears and presents an alternative, non-invasive method to measure pathogen prevalence in wild populations.

To optimize detection of low concentrations of parasite DNA, short amplicons in of DNA were targeted. Plasmodium species have a small mitochondrial genome (mtDNA), spanning only $6 \mathrm{~kb}$ but with copy numbers ranging from 20 to 100 per parasite [35, 36], whereas other common molecular targets (i.e., 18S rRNA) are present in low copy numbers [37]. Several primers that amplified segments greater than $700 \mathrm{bp}$ were unsuccessful in amplifying parasite DNA. The primer set with the highest sensitivity targetted the mitochondrial ssrRNA. Although primers detecting ssrRNA had higher sensitivity, species identity had to be determined with cytb isolates. The ssrRNA region of Plasmodium has been shown to be inaccurate at identifying Plasmodium species [38]. The amplicon length of cytb also affected the ability to determine species-identification became impossible with shorter amplicons. For diagnostics of malaria infection, the results of this study show that a primary screening with ssrRNA to detect infections is most accurate. Positive samples can then be identified with cytb amplicons.

Malaria infections are notoriously hard to detect in macaques by microscopy. Splenectomy was a common procedure historically to increase parasitaemia for detection of parasites and for work in the laboratory [39]. Chronic infections lasting for years are believed to be characteristic of several species of macaque Plasmodium [11]. This study demonstrates detection in naturally infected populations and shows that even low level infections can be detected.

The protocols outlined here will enable a more critical examination of the epidemiology of malaria in wild primate populations. Primate malaria research has relied on observations of mostly adult animals and, analogous to humans, the burden of malaria may fall on young animals. In fact, a recently published paper demonstrates anaemia and high parasitaemia associated with Plasmodium reichnowi in a juvenille chimpanzee [40]. A distinct age-class-prevalence curve has been recorded in howler monkeys, Alouatta species, from Panama [41] and chimpanzees, Pan troglodytes, in Cameroon [42]. More work in wild primate populations will inform the natural course of infections across the diversity of parasites. Epidemiology will most likely reflect a combination of host susceptibility (age, immune status, reproductive status, etc.), pathogen characteristics (periodicity, peak parasitaemia) and local environment affecting the epidemiology.

Using non-invasive faecal samples poses several challenges for evaluating the epidemiology of primate malaria. A direct comparison of faecal Plasmodium DNA and blood parasitaemia is not possible, and variation between timepoints within an individual is expected to be much greater than observed in the blood [41]. In laboratory-infected mice, Plasmodium DNA can be isolated during the pre-erythocytic phase, suggesting that presence in faecal samples is not indicative of an active infection [41]. Experimental infections of Japanese macaques [40] also demonstrate that Plasmodium DNA is detectable in faeces for days after an animal is treated and peripheral blood is negative. Although this study did not support previous findings, researchers are cautioned from drawing conclusions about the epidemiology of malaria from Plasmodium isolated from faecal samples.

In contrast to a study of an experimentally $P$. knowlesiinfected Macaca fuscata [43], parasite DNA was never found in faeces of uninfected macaques. In the experimental host, $P$. knowlesi DNA was detected in faecal samples for 12 days after the parasites were no longer present in blood samples. Abkallo and colleagues [44] concluded that parasite clearance caused accumulation of Plasmodium DNA in the gall bladder that was slowly excreted into faeces via bile. However, there were no false positives in faecal samples of naturally infected macaques in this study. This may reflect the chronicity of infections in these natural hosts and suggests that detection in faeces can be used to infer active infection in naturally infected macaques.

Other sources of non-invasive samples may have higher sensitivity, but there is a trade-off for ease of collection. In humans, sensitivity of PCR in saliva samples can reach $85 \%$ [45, 46], with an ELISA study reporting $100 \%$ sensitivity (although low sample size, $\mathrm{n}=8$ ) [47]. Higher parasitaemias increase probability in detecting parasites [48], so these methods may not be as robust with chronic infections. Protocols for sampling saliva in wild macque populations have been developed [49], and could be used in malaria-endemic populations for higher sensitivity in non-invasive screening.

\section{Conclusions}

Detection of Plasmodium DNA from faecal samples is complicated by degradation of DNA, absence of a clear relationship between parasitaemia and presence in faecal samples, and chronic infections in natural populations. These challenges require using robust extraction methods 
and amplifying short segments of DNA. This study demonstrates that amplification of parasite DNA is repeatable, even with low parasitaemia. Sensitivity of faecal screening is significantly higher than thin blood smears and is more tractable for field surveys. Plasmodium DNA can be amplified from faecal samples of naturally infected macaques. Repeated samples from individuals improves the ability to detect malaria infections and could improve understanding of malaria epidemiology in wild primates.

\section{Additional files}

Additional file 1: Raw data of long-tailed macaque (Macaca fascicularis) malarias. Includes surveys of Plasmodium coatneyi, P. cynomolgi, P. fieldi, P. knowlesi, and $P$. inui in natural hosts and humans across Southeast Asia.

Additional file 2: Non-invasive surveys for primate malarias. Raw data from studies that quantified Plasmodium detection from non-invasive samples.

Additional file 3: Optimal storage techniques. Data on DNA yield from faecal samples stored with four different protocols that varied in temperature and media.

\section{Authors' contributions}

CLF, APD and JES conceived of the study and participated in its design and coordination. DI, LR and US coordinated and collected samples. JES and LSM carried out the molecular genetic studies. CLF performed the statistical analysis and drafted the manuscript. All authors read and approved the final manuscript.

\section{Author details}

${ }^{1}$ Eijkman Institute for Molecular Biology, Jakarta, Indonesia. ${ }^{2}$ Department of Ecology and Evolutionary Biology, Princeton University, Princeton, NJ 08544 , USA. ${ }^{3}$ Pusat Studi Satwa Primata, Institut Pertanian Bogor, Bogor, Indonesia.

\section{Acknowledgements}

Funding for this collaboration was generously provided by the US Civilian Research and Development Foundation (CRDF Global) with support from the US Department of State. The opinions, findings and conclusions stated herein are those of the authors and do not necessarily reflect those of CRDF Global or the United States Department of State. JES and LSM were funded by a grant from the Indonesian government through the Ministry of Research Technology and Higher Education. CLF was funded by the National Defense Science and Engineering Graduate Research Fellowship and the Princeton University Center for Health and Wellbeing. The research was conducted with the approval of the Eijkman Institute for Molecular Biology Ethics Committee and Pusat Studi Satwa Primata, Institut Pertanian Bogor, Animal Care Committee.

\section{Competing interests}

The authors declare that they have no competing interests.

Received: 14 June 2015 Accepted: 22 August 2015

Published online: 12 October 2015

\section{References}

1. Gómez JM, Nunn CL, Verdú M. Centrality in primate-parasite networks reveals the potential for the transmission of emerging infectious diseases to humans. Proc Natl Acad Sci USA. 2013;110:7738-41.

2. Pedersen A, Davies T. Cross-species pathogen transmission and disease emergence in primates. EcoHealth. 2009;6:496-508.

3. Jones KE, Patel NG, Levy MA, Storeygard A, Balk D, Gittleman JL, et al. Global trends in emerging infectious diseases. Nature. 2008;451:990-3.
4. Wolfe ND, Dunavan CP, Diamond J. Origins of major human infectious diseases. Nature. 2007;447:279-83.

5. Heldstab A, Rüedi D, Sonnabend W, Deinhardt F. Spontaneous generalized Herpesvirus hominis infection of a lowland gorilla (Gorilla gorilla gorilla). J Med Primatol. 1981;10:129-35.

6. Ramsay E, Stair EL, Castro AE, Marks MI. Fatal Herpesvirus hominis encephalitis in a white-handed gibbon. J Am Vet Med Assoc. 1982;181:1429-30.

7. Goldberg TL, Gillespie TR, Rwego IB, Wheeler E, Estoff EL, Chapman CA Patterns of gastrointestinal bacterial exchange between chimpanzees and humans involved in research and tourism in western Uganda. Biol Conserv. 2007;135:511-7.

8. Köndgen S, Kühl H, N'Goran PK, Walsh PD, Schenk S, Ernst N, et al. Pandemic human viruses cause decline of endangered great apes. Curr Biol. 2008:18:260-4.

9. Choi YK, Simon MA, Kim DY, Yoon BI, Kwon SW, Lee KW, Seo IB. Fatal measles virus infection in Japanese macaques (Macaca fuscata). Vet Pathol. 1999;36:594-600.

10. Faust C, Dobson A. Primate malarias: diversity, distribution and implications for zoonotic Plasmodium. One Health. In Press.

11. Coatney GR, Collins WE, Warren M, Contacos PG. The Primate Malarias. Washington DC: US Government Printing Office; 1971.

12. Guimaraes L, Bajay M, Wunderlich G, Bueno M, Rohe F, Catao-Dias J, Neves A, Malafronte R, Curado I, Kirchgatter K. The genetic diversity of Plasmodium malariae and Plasmodium brasilianum from human, simian and mosquito hosts in Brazil. Acta Trop. 2012;124:27-32.

13. Fandeur T, Volney B, Peneau C, De Thoisy B. Monkeys of the rainforest in French Guiana are natural reservoirs for P-brasilianum/P-malariae malaria. Parasitology. 2000;120:11-21.

14. Volney B, Pouliquen JF, De Thoisy B, Fandeur T. A sero-epidemiological study of malaria in human and monkey populations in French Guiana. Acta Trop. 2002;82:11-23.

15. Prugnolle F, Rougeron V, Becquart P, Berry A, Makanga B, Rahola N, et al. Diversity, host switching and evolution of Plasmodium vivax infecting African great apes. Proc Natl Acad Sci USA. 2013;110:8123-8.

16. Eyles DE, Laing ABG, Warren M, Sandosham AA. Malaria parasites of the Malayan leaf monkeys of the genus Presbytis. Med J Malaya. 1962;17:85-6.

17. Putaporntip C, Jongwutiwes S, Thongaree S, Seethamchai S, Grynberg P, Hughes AL. Ecology of malaria parasites infecting Southeast Asian macaques: evidence from cytochrome b sequences. Mol Ecol. 2010;19:3466-76.

18. Eyles DE, Laing ABG, Dobrovolny CG. The malaria parasites of the pigtailed macaque, Macaca nemestrina nemestrina (Linnaeus), in Malaya. Indian J Malariol. 1962;16:285-98.

19. Sinton JA, Mulligan HW. A critical review of the literature relating to the identification of the malarial parasites recorded from monkeys of the families Circopithecidae and Colobidae. Rec Malar Surv India. 1933:3:357-80.

20. Lee K-S, Divis PCS, Zakaria SK, Matusop A, Julin RA, Conway DJ, Cox-Singh J, Singh B. Plasmodium knowlesi: reservoir hosts and tracking the emergence in humans and macaques. PLoS Pathog. 2011;7:e1002015.

21. Vythilingam I, Lim YAL, Venugopalan B, Ngui R, Leong C, Wong M, et al. Plasmodium knowlesi malaria an emerging public health problem in Hulu Selangor, Selangor, Malaysia (2009-2013): epidemiologic and entomologic analysis. Parasit Vectors. 2014;7:436.

22. William T, Rahman HA, Jelip J, Ibrahim MY, Menon J, Grigg MJ, et al. Increasing incidence of Plasmodium knowlesi malaria following control of P. falciparum and P. vivax Malaria in Sabah, Malaysia. PLoS Negl Trop Dis. 2013;7:e2026

23. Prugnolle F, Durand P, Neel C, Ollomo B, Ayala F, Arnathau C, et al. African great apes are natural hosts of multiple related malaria species, including Plasmodium falciparum. Proc Natl Acad Sci USA. 2010;107:1458-63.

24. Tazi L, Ayala FJ. Unresolved direction of host transfer of Plasmodium vivax v. P. simium and P. malariae v. P. brasilianum. Infect Genet Evol. 2011;11:209-21.

25. Liu W, Li Y, Learn GH, Rudicell RS, Robertson JD, Keele BF, et al. Origin of the human malaria parasite Plasmodium falciparum in gorillas. Nature. 2010;467:420-5. 
26. Liu W, Li Y, Shaw KS, Learn GH, Plenderleith LJ, Malenke JA, et al. African origin of the malaria parasite Plasmodium vivax. Nat Commun 2014;5:1-10.

27. WHO. World Malaria Report 2014. Geneva: World Health Organization; 2014. p. 1-242.

28. Lane $\mathrm{KE}$, Holley $\mathrm{C}$, Hollocher $\mathrm{H}$, Fuentes A. The anthropogenic environment lessens the intensity and prevalence of gastrointestinal parasites in Balinese long-tailed macaques (Macaca fascicularis). Primates. 2011;52:117-28.

29. Salyer SJ, Gillespie TR, Rwego IB, Chapman CA, Goldberg TL. Epidemiology and molecular relationships of Cryptosporidium spp. in people, primates, and livestock from Western Uganda. PLoS Negl Trop Dis. 2012;6:e1597.

30. Gillespie TR. Noninvasive assessment of gastrointestinal parasite infections in free-ranging primates. Int J Primatol. 2006;27:1129-43.

31. Jirků M, Pomajbíková K, Petrželková KJ, Hůzová Z, Modrý D, Lukeš J. Detection of Plasmodium spp. in human feces. Emerg Infect Dis. 2012;18:634-6.

32. De Nys HM, Calvignac-Spencer S, Thiesen U, Boesch C, Wittig RM, Mundry $\mathrm{R}$, Leendertz $\mathrm{FH}$. Age-related effects on malaria parasite infection in wild chimpanzees. Biol Lett. 2013;9:20121160.

33. Wilson E. Probable inference, the law of succession, and statistical inference. J Am Statistical Assoc. 1927;22:209-12.

34. Team RC. R: a language and environment for statistical computing. Vienna: R Foundation for Statistical Computing; 2013.

35. Vaidya AB, Arasu P. Tandemly arranged gene clusters of malarial parasites that are highly conserved and transcribed. Mol Biochem Parasitol. 1987;22:249-57.

36. Preiser PR, Wilson RJ, Moore PW, McCready S, Hajibagheri MA, Blight KJ, et al. Recombination associated with replication of malarial mitochondrial DNA. EMBO J. 1996;15:684-93.

37. Langsley G, Hyde JE, Goman M, Scaife JG. Cloning and characterisation of the rRNA genes from the human malaria parasite Plasmodium falciparum. Nucleic Acids Res. 1983;11:8703-17.

38. Imwong M, Tanomsing N, Pukrittayakamee S, Day NPJ, White NJ, Snounou G. Spurious amplification of a Plasmodium vivax small subunit RNA gene by use of primers currently used to detect P. knowlesi. J Clin Microbiol. 2009;47:4173.
39. Collins WE, Skinner JC, Broderson JR, Filipski VK, Morris CM, Stanfill PS, McWilson W. Susceptibility of Macaca fascicularis monkeys from Mauritius to different species of Plasmodium. J Parasitol. 1992;78:505-11.

40. Herbert A, Boundenga L, Meyer A, Moukodoum DN, Okouga AP, Arnathau $C$, et al. Malaria-like symptoms associated with a natural Plasmodium reichenowi infection in a chimpanzee. Malar J. 2015;14:220.

41. Porter J Jr, Johnson C, De Sousa L. Prevalence of malaria in Panamanian primates. J Parasitol. 1966;52:669-70.

42. De Nys HM, Calvignac-Spencer S, Boesch C, Dorny P, Wittig RM, Mundry $\mathrm{R}$, et al. Malaria parasite detection increases during pregnancy in wild chimpanzees. Malar J. 2014;13:413.

43. Kawai S, Sato M, Kato-Hayashi N, Kishi H, Huffman MA, Maeno Y, et al. Detection of Plasmodium knowlesi DNA in the urine and faeces of a Japanese macaque (Macaca fuscata) over the course of an experimentally induced infection. Malar J. 2014;13:373.

44. Abkallo HM, Liu W, Hokama S, Ferreira PE, Nakazawa S, Maeno Y, et al. DNA from pre-erythrocytic stage malaria parasites is detectable by PCR in the faeces and blood of hosts. Int J Parasitol. 2014;44:467-73.

45. Putaporntip C, Buppan P, Jongwutiwes S. Improved performance with saliva and urine as alternative DNA sources for malaria diagnosis by mitochondrial DNA-based PCR assay. Clinical Microbiolol Infect. 2011;17:1484-91.

46. Singh R, Savargaonkar D, Bhatt R, Valecha N. Rapid detection of Plasmodium vivax in saliva and blood using loop mediated isothermal amplification (LAMP) assay. J Infection. 2013;67:245-7.

47. Fung AO, Damoiseaux R, Grundeen S, Panes JL, Horton DH, Judy JW, et al. Quantitative detection of PfHRP2 in saliva of malaria patients in the Philippines. Malar J. 2012;11:175.

48. Nwakanma DC, Gomez-Escobar N, Walther M, Crozier S, Dubovsky F, Malkin $E$, et al. Quantitative detection of Plasmodium falciparum DNA in saliva, blood, and urine. J Infect Dis. 2009;199:1567-74.

49. Simons ND, Lorenz JG, Sheeran LK, Li JH, Xia DP, Wagner RS. Noninvasive saliva collection for DNA analyses from free-ranging Tibetan Macaques (Macaca thibetana). Am J Primatol. 2012;74:1064-70.

50. IUCN: Red List of Threatened Species.

51. Dorai-Raj S: binom: Binomial Confidence Intervals For Several Parameterizations. R package version 1.1-1 edn 2014.

\section{Submit your next manuscript to BioMed Central and take full advantage of:}

- Convenient online submission

- Thorough peer review

- No space constraints or color figure charges

- Immediate publication on acceptance

- Inclusion in PubMed, CAS, Scopus and Google Scholar

- Research which is freely available for redistribution

Submit your manuscript at

www.biomedcentral.com/submit

C) BioMed Central 